\title{
The morphological and phenological performance of different cotton genotypes under different plant density
}

\author{
Arvind Kumar ${ }^{1 *}$, A. P. Karunakar ${ }^{1}$, Anil Nath $^{2}$ and Bolta Ram Meena ${ }^{2}$ \\ ${ }^{1}$ Department of Agronomy, Dr. Panjabrao Deshmukh Krishi Vidyapeeth Akola-444104 (Maharashtra), INDIA \\ ${ }^{2}$ Department of Agronomy, Govind Ballabh Pant University of Agriculture and Technology, Pantnagar-263145 \\ (Uttarakhand), INDIA \\ *Corresponding author. E-mail: arvindbishnoi29e@gmail.com
}

Received: January 13, 2017; Revised received: May 30, 2017; Accepted: October 13, 2017

\begin{abstract}
The field experiment conducted with different plant density and different Genotypes showed significant differences in their morphological characters and phenological characters. Among the genotypes, AKA-7 possessed higher plant height $(116.4 \mathrm{~cm})$, No. of sympodia $\left(19.27\right.$ plant $\left.^{-1}\right)$ and leaf area index (3.628) compared to other genotypes but leaf area (33.02 dm- $\left.{ }^{2}\right)$ and dry matter weight (103.21 g/plant) were recorded higher with genotype Balwan. However, Normal plant density $(100 \%)$ was registered higher plant height $(102.6 \mathrm{~cm})$, no of sympodia (17.33 plant $\left.^{-1}\right)$, leaf area $\left(27.02 \mathrm{dm}^{2}\right)$ and dry matter weight $(58.13 \mathrm{~g} /$ plant) but higher leaf area index (3.430) was recorded with higher plant density (200\%). Among the genotypes, AKH-081 was comparatively earlier in phenological characters i.e. first square (47.9 days), first flower (67.9 days), first boll burst (116.1 days), first picking (128.7 days) and final picking (178 days). However, Higher planting density (200\%) was recorded earlier in first square (49.3 day), first flower (67.8 days), first boll burst (116.9 days), first picking (130.6 day) and final picking (179.7 days). On the basis of this experiment, genotype Balwan and normal planting density level (100\%) recorded higher morphological development wherever phenological development recorded earliar with the each respective phenophase in the Genotype AKH-081 and highest planting density level (200\%).
\end{abstract}

Keywords: Genotypes, Plant density, Plant morphology, Plant phenology

\section{INTRODUCTION}

Cotton, the 'white gold' or the 'king of the fiber' accounts for $75 \%$ of the fiber used in textile industry and contributes $4 \%$ of the Indian GDP. It is cultivated in tropical and subtropical regions of more than 80 countries of the world (Sankarnaryanan et al., 2010). It plays a prominent role in the rural, national and international economy. Planting density system is adopted for deciding the suitable morphological and phenological characters according to the climatic condition and resources availability. Due to long duration of cotton genotypes. The morphological and phenological development is affected by the incidents of pest and diseases, moisture stress and environmental variabilities as rainfall and temperature that causes higher cost of cultivation and low farm profitability. So to overcome above agronomic problems, selection of the morphological characters viz; plant height $(\mathrm{cm})$, no. of sympodia per plant, leaf area per plant $\left(\mathrm{dm}^{2}\right)$, leaf area index and dry matterproduction ( $\mathrm{g} \mathrm{plant}^{-1}$ ) and the phenologicalcharacters viz; squares formations, flowering, boll formation and boll bursting and maturity are important aspects to improving the performance of cotton genotypes under different planning density that well suited under rainfed condition (Patil and Patil, 2007).
Compact cotton genotypes require limited space to grow than tall and robust cotton plant so its important to decide the optimum plant density for compact cotton plant to generate maximum output and net profit. Along the morphological development, phenological development must be important aspect so an optimum plant density also requires todeciding the crop maturity, harvesting and crop growth period of cotton (Rose Roche, 2003). In addition, these compact early maturing cotton can be harvested in two or three picking because of their short stature, lesser vegetative growth and synchronous maturity. So these compact genotypes are ideally suited for machine pickings and high density planting (Patil and Patil, 2007). High density planting system gained further acceptance after the introduction of cotton hybrids. Research experiment conducted by Silvertooth (1999) indicated that with increase in plant density yield per unit area increased to an upper limit (optima), plateaued later and ultimately declined. The optimum plant density in this parabolic (density - yield) relationship was a function of the genotype, soil type, climate and management (Venugopalan et al., 2013). In recent years studies opined that potential of $B t$ cotton is constrained under rainfed conditions in India and even though yields increase with irrigation this does not necessarily translate 
into an increase in economic benefits received by small holder farmers. Since cotton breeding has not concentrated on developing genotypes especially for high density planting in India, some promising genotypes of both Gossypiumhirsutumand Gossypiumarboreum needs to be evaluated locally for their morphological and phenological performance at higher planting densities under rainfed conditions. So this experiment was carried out to know about the morphological and phenological performance of Hirsutem, Arboreum and Bt cotton under the high density planting system in rainfed conditions.

\section{MATERIALS AND METHODS}

Study site and climatic conditions: A field experiment was conducted during 2015-16 under rainfed conditions at the All India Coordinated Research Project on Agrometeorology (AICRPAM), Dr.Panjabrao Deshmukh Krishi Vidyapeeth, Akola, Maharastra to study the morphology and phenologyof different cotton genotypes. The experimental trial site is situated in the sub-tropical zone at the latitude of $22^{0} 42^{\prime}$ North longitude of $77^{0} 02^{\prime}$ 'East. The altitude of the place is 307.41 meter above mean sea level. The climate of Akola is semi-arid and characterized by three distinct seasons viz., hot and dry summer from March to May, warm and rainy monsoon from June to October and mild cold winter from November to February. The normal mean monthly maximum temperature is $42.3^{\circ} \mathrm{C}$ during the hottest month (May) while the normal mean monthly minimum temperature is $11.1^{\circ} \mathrm{C}$ in the coldest month (December). Most of the rain received from south-west monsoon during June to October with mean annual normal precipitation of $788.9 \mathrm{~mm}$ received in 43.7 rainy days (Average of 30 years, 1981-2010)The maximum mean daily evaporation observedin may month $(15.6 \mathrm{~mm})$ and lowest in the December month $(4$ $\mathrm{mm})$. The mean wind velocity reported maximum during November $\left(3.4 \mathrm{~km} \mathrm{hr}^{-1}\right)$ and lowest during June (13.5 $\left.\mathrm{km} \mathrm{hr}^{-1}\right)$. Relative humidity attains the maximum value (69-87 \%) during the south west monsoon months (June-September) and the minimum (15-19\%) during summer months (March-May).

Properties of Soil: The soil of experimental plot was clayey. The fertility status of the soil indicates that the soil was medium in organic carbon $\left(5.7 \mathrm{~g} \mathrm{~kg}^{-1}\right)$, low in available nitrogen $(210.7 \mathrm{Kg} / \mathrm{ha})$ and medium available phosphorus $(18.3 \mathrm{Kg} / \mathrm{ha})$ and moderately high in available potassium $(288.6 \mathrm{Kg} / \mathrm{ha})$. With medium deep black cotton soil with slightly saline ph (8.3) and EC (0.24 $\mathrm{dSm}^{-1}$ )

Expermantal design: This experiment laid out in a Factorial randomized block design that consisted 3 genotypes viz.Arboreum (AKA-7), Hirsutum (AKH081) and Bt cotton (BALWAN) (Source ; Cotton research unit, Dr. PDKV, Akola,Maharastra) with 3 replication and three planting density level at $100 \%$ planting density level ( For non Bt genotypes 111111 plants $\mathrm{ha}^{-1}$ and for Bt genotype 24691 plant ha ${ }^{1}$ ) ,150\% planting density level ( For non Bt genotypes 166666 plants ha ${ }^{-1}$ and for Bt genotype 37037 plant ha ${ }^{1}$ ) and $200 \%$ planting density level ( For non Bt genotypes 222222 plants $\mathrm{ha}^{-1}$ and for Bt genotype 49382 plant $\left.\mathrm{ha}^{-1}\right)$. Compact cotton genotypes were selected based on growth and morphological characters like; plant height $(\mathrm{cm})$, No. of sympodia plant $^{-1}$, leaf area $\left(\mathrm{dm}^{2}\right.$ plant $\left.^{-1}\right)$, leaf area index and dry matter weight ( $\mathrm{g}$ per plant) and for phenological characters as; first square, first flower, first boll burst, first picking and final picking were selected for study of morphophenological responses of cotton varieties and different plant density. Observations were taken from randomly selected Five plants from each plot. The data were analyzed as per Gomez and Gomez (1984) with the help of computer.

\section{RESULTS AND DISCUSSION}

Plant height (cm): Data on plant height (cm) as influenced by different treatments recorded periodically are presented in Table 1.Plant height increased as the crop advanced in age. Mean plant height increased from $14.5 \pm 1.26 \mathrm{~cm}$ at 30 Days After Emergence (DAE) to $101.6 \pm 1.56 \mathrm{~cm}$ at harvest stage. The rate of increase in plant height was the maximum between 60 to $90 \mathrm{DAE}$. Subsequently the rate of increase of plant height was gradual decreasing towards maturity stage.

Genotype: Plant height was significantly $(\mathrm{P}=0.05)$ influenced throughout the crop growth period by different genotypes. At 30 DAE, Bt cotton Balwan recorded significantly higher plant height than AKH-081 and AKA-7 which were at par. Subsequently at 60, 90, 120,150 DAE and at harvest stage, arboreum genotype AKA-7 attained significantly higher plant height over the remaining two genotypes. AKH-081 recorded the least plant height. Balwan recorded significantly higher plant height than AKH-081. Differences observed for plant height among cotton genotypes can be primarily attributed to variation in genetic makeup of plants. Moreover, different genotypes respond in different degrees to the abiotic and biotic factors. Moola and Giri (2006) also observed that plant height has significant differences in of Bt and non Btcotton genotypes due to the growth habits of different cultivars and response to environment.

Plant density: Differences due to plant density on plant height were found to be non-significant at 30, 60 and 90 DAE. Subsequently, from 90 DAE to harvest stage, maximum plant height was recorded in normal planting density with $100 \%$ population (P1) $(107.3 \pm 1.56 \mathrm{~cm})$, which was significantly superior over high density planting at $200 \%$ of normal population $(\mathrm{P} 3)(95.6 \pm 1.87 \mathrm{~cm})$ and at par with high density planting with $150 \%$ population $(\mathrm{P} 2)(102 \pm 1.96 \mathrm{~cm})$. Treatments P2 and P3 varied non-significantly be- 
Table 1. Plant height $(\mathrm{cm})$, Sympodial branches plant ${ }^{-1}$, Leaf area plant ${ }^{-1}\left(\mathrm{dm}^{2}\right)$, Leaf area index and Total dry matter accumulation plant $^{-1}(\mathrm{~g})$ as influenced by different cotton genotypes and different planting density.

\begin{tabular}{|c|c|c|c|c|c|}
\hline \multirow[t]{2}{*}{ Treatment } & $\begin{array}{l}\text { Plant height } \\
(\mathrm{cm})\end{array}$ & $\begin{array}{c}\text { Sympodial branch- } \\
\text { es plant }^{-1}\end{array}$ & $\begin{array}{c}\text { Leaf area } \\
\text { plant }^{-1}\left(\mathrm{dm}^{2}\right)\end{array}$ & $\begin{array}{c}\text { Leaf area } \\
\text { index }\end{array}$ & $\begin{array}{c}\text { Total dry matter accu- } \\
\text { mulation plant }{ }^{-1}(\mathrm{~g})\end{array}$ \\
\hline & 120 DAE & 120 DAE & $120 \mathrm{DAE}$ & 120 DAE & 120 DAE \\
\hline \multicolumn{6}{|l|}{ Genotype } \\
\hline $\mathrm{V}_{1}-\mathrm{AKH} 081$ & $76.7 \pm 1.53$ & $12.20 \pm 1.34$ & $20.05 \pm 1.08$ & $3.439 \pm 0.84$ & $32.86 \pm 1.24$ \\
\hline $\mathrm{V}_{2}$-AKA 7 & $116.4 \pm 1.72$ & $19.27 \pm 1.18$ & $21.20 \pm 1.26$ & $3.628 \pm 0.65$ & $38.11 \pm 1.16$ \\
\hline $\mathrm{V}_{3}$-Balwan & $98.4 \pm 1.26$ & $16.60 \pm 1.18$ & $33.02 \pm 1.43$ & $1.197 \pm 0.56$ & $113.70 \pm 2.12$ \\
\hline $\mathrm{SE} \pm$ & 3.4 & 0.61 & 0.51 & 0.069 & 1.33 \\
\hline $\mathrm{CD}(\mathrm{P}=0.05)$ & 10.3 & 1.84 & 1.53 & 0.207 & 3.98 \\
\hline \multicolumn{6}{|l|}{ Plant density } \\
\hline $\mathrm{P}_{1}-\mathrm{NP} 100 \%$ & $102.6 \pm 1.56$ & $17.33 \pm 1.43$ & $27.02 \pm 1.72$ & $2.048 \pm 0.59$ & $69.74 \pm 1.89$ \\
\hline $\mathrm{P}_{2}$-HDP $150 \%$ & $97.1 \pm 1.38$ & $15.84 \pm 1.26$ & $24.87 \pm 1.54$ & $2.787 \pm 0.88$ & $61.47 \pm 1.71$ \\
\hline $\mathrm{P}_{3}$-HDP $200 \%$ & $91.8 \pm 1.26$ & $14.89 \pm 1.14$ & $22.39 \pm 1.29$ & $3.430 \pm 0.96$ & $53.46 \pm 1.58$ \\
\hline $\mathrm{SE} \pm$ & 3.4 & 0.61 & 0.51 & 0.069 & 1.33 \\
\hline $\mathrm{CD}(\mathrm{P}=0.05)$ & 10.3 & 1.84 & 1.53 & 0.207 & 3.98 \\
\hline GM & $97.2 \pm 1.28$ & $16.02 \pm 1.32$ & $24.76 \pm 1.31$ & $2.755 \pm 0.96$ & $61.56 \pm 1.68$ \\
\hline
\end{tabular}

Table 2. Crop phenology as influenced by different cotton genotypes and different planting density.

\begin{tabular}{lccccc}
\hline \multirow{2}{*}{ Treatment } & \multicolumn{5}{c}{ Duration (days) } \\
\cline { 2 - 6 } & First square & First flower & First boll burst & First picking & final picking \\
\hline Genotype & & & & & \\
\hline V $_{1}$-AKH 081 & $47.9 \pm 2.21$ & $67.9 \pm 1.67$ & $116.1 \pm 2.16$ & $128.7 \pm 1.86$ & $178.0 \pm 1.56$ \\
V $_{2}$-AKA 7 & $50.2 \pm 1.56$ & $69.1 \pm 2.86$ & $122.2 \pm 2.86$ & $138.1 \pm 2.25$ & $191.3 \pm 2.14$ \\
V 3 -Balwan & $51.2 \pm 2.01$ & $69.1 \pm 2.21$ & $118.1 \pm 1.64$ & $131.7 \pm 1.94$ & $180.7 \pm 1.49$ \\
\hline Plant density(\%) & & & & & \\
\hline P 1 -NP 100\% & $50.4 \pm 1.68$ & $69.2 \pm 1.94$ & $120.3 \pm 2.14$ & $134.3 \pm 1.69$ & $186.0 \pm 2.02$ \\
P $_{2}$-HDP 150\% & $49.6 \pm 1.42$ & $69.1 \pm 1.71$ & $119.2 \pm 2.37$ & $133.6 \pm 1.62$ & $184.3 \pm 1.86$ \\
P -HDP 200\% & $49.3 \pm 1.38$ & $67.8 \pm 1.67$ & $116.9 \pm 2.24$ & $130.6 \pm 1.56$ & $179.7 \pm 1.79$ \\
GM & $\mathbf{4 9 . 8} \pm \mathbf{2 . 4 6}$ & $\mathbf{6 8 . 7} \pm \mathbf{1 . 3 2}$ & $\mathbf{1 1 8 . 8} \pm \mathbf{2 . 0 2}$ & $\mathbf{1 3 2 . 8} \pm \mathbf{1 . 2 5}$ & $\mathbf{1 8 3 . 3} \pm \mathbf{1 . 3 6}$ \\
\hline
\end{tabular}

$\mathrm{V}=$ Genotype; P:- Plant density( $\mathrm{NP}=$ Normal planting, $\mathrm{HDP}=$ High density planting)

tween them. Pradeep kumar et al. (2017) was observed that cotton seedlings tend to grow taller in thick stands. At harvest, plant heights in high density planting have the lowest average plant height because early canopy closure did not translate photosynthates for faster growth or development. Due to excessive competition forphoto-assimilates, high density planting attain lesser average plant height. (Rose Roche et al., 2003). Plant spacings directly influence soil moisture extraction, light interception, humidity and wind movement that influences plant growth and plant height. Zhang et al. (2014) observed that cotton plant height decreased with increased plant density. Singh et al. (2015) also reported that plant height attained its apogee at wider spacing.

Number of sympodial branches: Sympodial branches plant $^{-1}$ increased with the age of crop and attained maximum value at 120 DAE. Mean number of sympodial branches plant ${ }^{-1}$ increased from $6.63 \pm 1.12$ at 60 DAE to $16.02 \pm 1.32$ at 120 DAE. The relevant data on number of sympodial branches per plant are presented in Table 1.

Genotype: The effect of genotype on sympodial branches plant ${ }^{-1}$ was recorded significant $(\mathrm{P}=0.05)$ among different genotype at $60 \mathrm{DAE}, 90 \mathrm{DAE}$ and 120 DAE. Genotype AKA 7 (V2) recorded maximum number of sympodial branches plant $^{-1} 7.64 \pm 1.26$,
$18.20 \pm 1.56$ and $19.27 \pm 1.18$ from 60,90 and120 DAE respectively and it was significantly superior over Balwan (V3) and AKH 081 (V1).Balwan produced significantly more number of sympodial branches plant ${ }^{-1}$ as compared to AKH 081. The differences in number of sympodial branches plant-1 can be affected by different factors viz; differences in genetic makeup of the genotypes, wherein in due to more plant height and duration, number of sympodial branches also increases relative to the different genotypes. Copur (2006), Giri et al. (2008) and Bharathi et al. (2012) observed significant difference in sympodial branches per plant in cotton genotypes due to morphological differenciation,apical dominance, plant height and resourses availability to different cotton genotypes.

Plant density: The number of sympodial branches plant-1 was found to vary non significantly among different plant densities at 60 DAE and 90 DAE. But numerically normal planting at a level of $100 \%$ was recorded more number of sympodial branches plant $^{-1}$ $(16.22 \pm 1.20)$ than high density planting at a level of $150 \%(14.93 \pm 1.40)$ and $200 \%(14.31 \pm 1.32)$ and 90 DAE.

At 120 DAE, normal plant density (100\%) recorded maximum number of sympodial branches plant $^{-1}$ $(17.33 \pm 1.42)$ at par with high density planting at 150 $\%(\mathrm{P} 2)[15.84 \pm 1.26]$ and significantly higher than high 
density planting at $200 \%(\mathrm{P} 3)[14.89 \pm 1.14]$. Treatments P2 and P3 were statistically at par (Statistical methods, Gomez and Gomez (1984)). Plant spacingsdirectly influences plantmoisture, light and space usethat causes excess competition for photoassimilates needed for growth and reproductive development. Plant resources competition causes lesser production of plant drymatter and new sympodial branching (Darawsheh et al 2007). Jagtap and Bhale (2011), Paslawar et al. (2015) and Shekar et al. (2015) also found that with increases the plant competition formoisture,light and space use causes low photosynthetes accumulation. Due to lesser photosynthetes accumulation, the production of new branches are reduced.

Leaf area per plant: Data pertaining to leaf area plant ${ }^{-1}\left(\mathrm{dm}^{2}\right)$ as influenced periodically by different treatments are presented in Table 1. The mean leaf area plant $^{-1}$ expanded progressively and reached to a maximum of $24.76 \pm 1.31 \mathrm{dm}^{2}$ at 120 DAE stage. The rate of increase in leaf area per unit time was maximum during growth period of 60 to 90 DAE stage.

Genotype: Different genotypes had significant $(\mathrm{P}=0.05)$ influence on the leaf area $\mathrm{dm}^{2}$ plant $^{-1}$ observed at 60,90 and 120 days after emergence of crop. At all the observed stages of observation Bt cotton genotype Balwan (V3) produced significantly higher leaf area plant $^{-1}(33.02 \pm 1.43)$ than hirsutum genotype AKH 081 (V1)(20.05 \pm 1.08$)$ and arboreum genotype AKA 7 (V2)(21.20 \pm 1.26$)$. The latter two genotypes produced statistically similar leaf area plant ${ }^{-1}$ at all the stages. BtBalwan and hirsutum AKH 081 genotypes have Broad-leaf expression while arboreum AKA 7 has okra leaf shape. However, AKA 7 genotype bears more number of leaves compensating for its comparatively lower area of individual okra leaf. Differences in leaf area plant ${ }^{-1}$ may be mainly ascribed to differences in genetic makeup of the genotypesviz; Short stature, number of leaves per plant and shape of leaf as the broad leaf charecters(Bt BALWAN and AKH-081) and okra type leaf charecters(AKA-7).

Plant density: Differences in leaf area plant ${ }^{-1}$ due to different planting densities were significant $(\mathrm{P}=0.05)$ and leaf area plant $^{-1}$ showed decreasing trend with increasing plant density (P1 to P3) due to lesser morphological developmentas lesser leaf development and lesser number of leaves at all the observed growth stages of the crop. Normal planting density (100\%) produced significantly higher leaf area plant ${ }^{-1}$ $(24.32 \pm 1.34)$ at all observed stages of crop growth. However, it was on par with high density planting at $150 \%$ of normal population (P2) $(22.62 \pm 1.66)$, except at $120 \mathrm{DAE}$, and statistically more over high density planting at $200 \%(\mathrm{P} 3)(20.82 \pm 1.81)$. Treatment $\mathrm{P} 2$ was statistically equivalent to P3 except at 120 DAE whereat it noted significantly higher leaf area plant $^{-1}$ than P3. Maximum leaf area plant ${ }^{-1}$ with lower plant density could be due to higher number of leaves plant ${ }^{-1}$ and better leaf expansion as a consequence of more favourable share of resources (moisture, light radiation and nutrients) by individual plant.

Leaf area index: Leaf area index characterizes the canopy-atmosphere interface, where most of the energy fluxes exchange. Leaf area index (LAI) was computed treatment wise from 30 to $120 \mathrm{DAE}$. The relevant data are presented in Table 1.

Genotype: Leaf area index was observed the maximum with AKH 081 that were $0.116 \pm 0.14$ and $1.901 \pm 0.28$ at 30 and 60 DAE respectively. At 90 and 120 DAE,LAI was found maximum with AKA 7 which is $3.363 \pm 0.85$ and $3.628 \pm 0.65$ respectively. However, both genotypes were statistically at par with each other and exhibited significantly higher LAI as compared to Bt cotton Balwan (V3). This could be mainly due to relatively wider plant spacing of Bt cotton genotype accommodating more ground area plant ${ }^{-1}$, although it produced significantly higher leaf area plant $-1$

Plant density: Plant density significantly $(\mathrm{P}=0.05)$ influenced the leaf area index. Leaf area index showed increasing trend with increasing plant density (P1 to P3) at all the observed growth stages. High density planting at $200 \%$ of normal population (P3) showed significantly higher leaf area index than $150 \%(\mathrm{P} 2)$ and normal $(100 \%)$ planting densities. Reduced ground area plant ${ }^{-1}$ with higher population densities caused more LAI in high density planting. This corroborates the findings of Zhang et al. (2014) who observed that cotton leaf area index increased but plant height decreased with plant density.

Dry matter weight per plant: Total dry matter production $\left(\mathrm{g}\right.$ plant ${ }^{-1}$ is the integral component of crop growth rate over the entire growth period, and it is related to grain yield $(\mathrm{Kg} / \mathrm{ha})$ by the harvest index. Relevant data to this character recorded at various stages are presented in Table 1 .

During the crop growing period increase in dry matter weightplant $^{-1}(\mathrm{~g})$ was continuous up to $150 \mathrm{DAE}$, from 2.28 to $68.23 \mathrm{~g}$. Subsequently at harvest it declined $(52.16 \mathrm{~g})$ due to leaf senescence and picking of burst bolls. The rate of increase was very slow up to 30 days $(3.34 \%)$. Thereafter it accelerated with stage of growth i.e. at 60 days $(26.71 \%), 90$ days $(64.86 \%)$ till 120 days $(90.22 \%)$. From 120 th day further increase till 150 DAE was comparatively small $(9.78 \%)$. Therefore the maximum quantitative increase in dry matter weight was observed between 60 to 90 DAE followed by 90 to 120 DAE.Bange et al (2004)observed that plant dry matter increases slowly at early crop growth stage but during maximum vegetative stage, dry matter production increase rapidly due to more light interception of light and less demand to reproductive organs after that at the reproductive stage and later dry matter accumulation rate decreases due to more demand to 
reproductive organs.

Genotype: Different genotypes showed significant differences in dry matter weight plant $^{-1}(\mathrm{~g})$ at various growth stages. Bt cotton Balwan (V3) accumulated significantly $(\mathrm{P}=0.05)$ higher dry matter weight plant $^{-1}$ (129.28 \pm 2.14$)$ as compared to $\mathrm{AKH} 081$ (V1) (35.18 \pm 1.56$)$ and AKA 7 (V2)(40.22 \pm 1.76$)$ at all stages of crop growth. Genotype AKA 7 recorded significantly higher dry matter weight plant ${ }^{-1}$ than AKH-081 (V1) 150 DAE, however, being statistically at par at 30 DAE and harvest stage. Bt cotton Balwan inherently produced comparatively more vegetative/reproductive growth in terms larger leaves, resultantly larger leaf area plant ${ }^{-1}$ and hence more photo-assimilates to cater greater number bolls plant ${ }^{-1}$ and higher boll weight consequently causing higher dry matter weight plant- 1 . Sisodia and Khamparia (2007), Giri et al. (2008) and Ban (2015) also reported significantly difference in drymatter production of different genotypes. Because different cotton genotypes have different growth habits and crop growth duration, moisture availability etc.

Effect of plant density: Total dry matter accumulation plant $^{-1}(\mathrm{~g})$ was significantly $(\mathrm{P}=0.05)$ influenced due to different plant densities at various growth stages of cotton. Cotton plants under normal planting density (P1) accumulated significantly higher dry matter plant ${ }^{1}(76.87 \pm 2.32)$ than both high planting densities of $150 \%$ (P2)(68.25 \pm 1.96$)$ and $200 \%$ (P3) of normal population $(59.56 \pm 1.28)$ at all observed crop growth stages. However, $150 \%(18.89 \pm 1.56)$ and $200 \%$ planting densities $(17.83 \pm 1.68)$ were at par at 30 and 60 DAE but subsequently from 90 DAE till harvest stage the former proved significantly

Plant spacing influences soil moisture extraction, light interception, soil nutrients use, canopy aeration etc. that causealteration of vegetative and reproductive development of a plant. Under high density planting, plants suffer to excessive competition for limited resources as sunlight, water and nutrients which translate into reduced photo-assimilates and hence lower dry matter production plant ${ }^{-1}$. Zhang et al. (2007) and Jadhav et al. (2015) opined that plant drymatter production decreases with increasing plant density due to resoures competition and lesser leaf area for photosythates production.

Crop Phenology: Occurrence of different phenophase of crop and its duration in days under different treatments is presented in Table 2.Mean number of days to different phenophase as first square, first flower, first boll burst, first picking and final picking was $49.8 \pm 2.46, \quad 68.7 \pm 1.32, \quad 118.8 \pm 2.02, \quad 132.8 \pm 1.25$ and $183.3 \pm 1.36$ days, respectively.

Genotype: Number of days required to attain different phenophase differed slightly among genotypes till first flower stage, subsequently magnitude of differences among genotypes increased till final picking stage.Days to first flower is not directly considered as yield component but days taken to first flower after emergence of the crop would ultimately influence the opening of bolls, thus helps in determining the earliness in maturity.Genotype Balwan $\left(\mathrm{V}_{3}\right)$ required more days to first square stage $(51.2 \pm 2.01$ days $)$ than the other two genotypes AKA 7 (50.2 \pm 1.56 days) and AKH 081(47.9 \pm 2.21 days). Genotype AKH-081 produced early flowering $(67.9 \pm 1.67$ days $)$ followed by genotypes AKA-7 (69.1 \pm 2.86 days) and Balwan (69.1 \pm 2.21 adys).First boll burst was observed earlier with genotype AKH-081 (116.1 \pm 2.16$)$ than genotype Balwan (118.1 \pm 1.64$)$ and AKA-7 (122.2 \pm 2.86$)$ because Genotype AKA-7 was suffered from marginal square/flower drop at first flush while genotype $\mathrm{AKH}$ 081 also encountered scattered square/flower drop of first flush that cause delay in AKA-7 to reach at first boll burst stage

Due to delay in first boll burst, Genotype AKA-7 required more days $(138.1 \pm 2.25)$ to reach at first picking stage than other Genotypes. Whereas Genotype AKH081 reached earlier to final picking stage $(178.0 \pm 1.56$ days) than Balwan (180.7 \pm 1.49 days) and AKA-7 (191.3 \pm 2.14 days) because earliness in reaches to different phenophases as first square initiation, first flower initition, first boll burst stage and first picking stage.Although average crop duration of all three genotypes is in the range of 150-160 days, increased crop duration observed in the present study might be due to the seasonal growing environment influences as rainfall variability. As such the variation in occurrence time of respective phenophase and also crop duration among genotypes are primarily due to their different inherent genetic expression; though modified and controlled by growing environment influences.

Plant density: The appearance of first floral bud (square) is considered as an important trait to assess earliness in cotton (Saleem et al., 2010). Many studies have reported that crop maturity occurred earlier with the increasing of the plant density. According to Rose Roche (2003) conceptually, the high density planting of Ultra Narrow Row reduces the time to crop maturity, as fewer bolls per plant need to be produced to achieve yields comparable to conventionally spaced cotton crops. Under high planting densities excessive competition for limited resources force the plants to pace through to maturity earlier.

Normal planting density $\left(\mathrm{P}_{1}-100 \%\right)$ required comparatively more number of days to attain different phenophase and reach maturity. Plants in thin stands grow large vegetative structures and more fruit load, as a result more time is required to set the crop and consequently maturity is delayed. There appears marginal difference (1 to 2 days) between $100 \%$ and $150 \%$ planting density in attainment of respective phenophase and maturity. In comparison with normal planting density $\left(\mathrm{P}_{1}\right)$, highest planting density of $200 \%$ population $\left(\mathrm{P}_{3}\right)$ reached earlier to first flower 
(67.8 \pm 1.67 day), first boll burst $(116.9 \pm 2.24$ days $)$, first picking (130.6 \pm 1.56 days) and final picking (179 \pm 1.79 days). According to Munir et al. (2015),number of days from planting to first floral bud initiations (squaring) were decreased by narrow spacing which might be due to increased inter-plant competition. These results also substantiated the findings of Bednarz et al. (2000) and Mygdakos et al. (2004), who reported that the earliness (early squaring or flowering) increased when row spacing decreased.

\section{Conclusion}

The present study observed that genotypes and plant density significantly influenced the morphological and phenological performance of different cotton genotypes. It was reported that genotype AKA-7 was significantly superior in plant height, number of sympodial branches per plant and leaf area index than other genotypes but in case of leaf area per plant and dry matter production per plant, genotype BALWAN was found superior over the rest of the genotypes that indicated that Balwan more efficiently utilizes the resources in rainfed region. Planting density at the of $100 \%$ reported maximum plant height, number of sympodial branches per plant, leaf area per plant and dry matter production per plant than other plant density. In case of phenological performance, genotype AKH-081 and planting density at the level of 200\% were best suited under rainfed conditions because it showed earliness in development of all phenological characters' as first square development, first flowering stage, first boll burst stage, at first picking and final picking stage.

\section{REFERENCES}

Ban, Yogesh G., D.P. Nawalkar, B.M. Mote, V. Kumar, A.V. Narwade, (2015). Crop phenology, thermal requirement, yield and fiber properties of cotton (Gossypiumhirsutum) genotypes as influenced by different environments, Ind. J. Plant Physiol., 20(2):137144.

Bange, M. P., and S. P. Milroy. (2004) "Growth and dry matter partitioning of diverse cotton genotypes." Field Crops Research. 87(1): 73-87.

Bednarz C. W., D.C. Bridges and S.M. Brown, (2000). Analysis of cotton yield stability across population densities. Agronomy Journal, 92:128-135.

Bharathi, S. G., M. V. Prasad Rao, S. RatnaKumari and V. Chenga Reddy, (2012). Influence of plant geometry and nitrogen levels on performance of cotton hybrids under rainfed condition in vertisols of Andhra Pradesh. $J$. Cotton Res. Dev. 26 (2): 204-206.

Copur, O., (2006). Determination of yield and yield components of some cotton cultivars in semi arid conditions Pak. J Biol. Sci., 9(14): 2572-2578.

Darawsheh M.K., Aivalakis G. and Bouranis D.L., (2007). Effect of cultivation system on cotton development, seed cotton production and lint quality. The European $J$. Plant Sci. and Biotechnology 1(2)-206-213.
Zhang Dongsheng, Lizhen Zhang, Jianguo Liu, Shuo Han, Qi Wang, Jochem Evers, Jun Liu, Wopke van der Werf, Long Li, (2014). Plant density affects light interception and yield in cotton grown as companion crop in young jujube plantations. Field Crops Research 169:132-139.

Giri, A. N, R.L. Aundhekar, P.S. Kapse and S. B. Suryavanshi, (2008). Response of Bt cotton hybrids to plant densities and fertilizer levels. J. Cotton Res. Dev. 22 (1): 45-47,

Gomez, K. A. and A. A. Gomez, (1984). Statistical procedure for Agricultural Research. An International Rice Research institute Book. A Wiley Inter Science Publication, New York.

Jadhav, S. G., B.A. Chavan and Y.M. Waghmare, (2015). Effect of plant spacing growth regulator and nutrient management on yield, quality and economics of Bt cotton. J. Cotton Res. Dev. 29 (1) :48-52.

Jagtap, D. N. and V. M. Bhale, (2011). Effect of different plant spacing and nitrogen levels on deshi cotton hybrid (Gossypiumarboreum L.). J. Agric. Sci.7: 123-125.

Moola, R. and A.N. Giri, (2006). Response of newly released cotton ( $G$. hirsutum) varieties to plant densities and fertilizer levels. J. Cotton Res. Dev. 20(1):85-86.

Munir, M. K., M. Tahir, M. F. Saleem and M.Yaseen, (2015). Growth, yield and earliness response of cotton to row spacing and nitrogen management. The Journal of Animal \& Plant Sciences, 25(3): 729-738.

Mygdakos, E., C. Avgoulas, K. Adamidis and G.Ekonomou, (2004). Cotton cultivation on narrow rows as an alternative culture method: Production and economics. J. Food Agric. \& Environ 2 :198-201.

Paslawar, A. N., A. S. Deotalu and P. W. Nemade, 2015. High density planting of cotton variety AKH -081 under rainfed condition of Vidharbha, Plant archives, 15 (2):1075-1077.

Patil, Basanagouda C., and S. S. Patil.(2007) "Performance of compact cotton genotypes (G. hirsutum) at three spacings and two moisture levels." World Cotton Research Conference-4, Lubbock, Texas, USA, 10-14 September 2007. International Cotton Advisory Committee (ICAC), 2007.

Pradeep Kumar, A.S. Karle, Deshraj Singh and Lalita Verma. (2017). Effect of High Density Planting System (HDPS) and Varieties on Yield, Economics and Quality of Desi Cotton. Int.J.Curr.Microbiol.App.Sci. 6(3): 233-238.

Rose, Roche, Michael Bange, Stephen Milroy and Graeme Hammer, (2003). Cotton growth in UNR systems. The Australian Cotton Grower, October-November 2003.

Saleem, M. F., et al. (2010) "Effect of different phosphorus levels on earliness and yield of cotton cultivars." Soil \& Environment. 29: 128-135.

Sankarnaryanan, K.P, raharaj C.S, Nalayani P., Bandyopodhy K.K and 80 Gopalakrishnan .N.(2010) Climate change and its effect on cotton (Gossipium sp.) Indian journal agriculture sciences, 80:561-575.

Shekar, K., M. Venkata Ramana, S.M. RatnaKumari, (2015). Response of hybrid cotton to chloromepiquat chloride and detopping under high density planting, Cotton Res. J. Dev. 29 (1) 84-86.

Silvertooth, J.C. (1999). Row Spacing, plant population, and yield relationships. Arizona cotton comments. Coop. Ext., Univ. Arizona, Tucson, USA. Online available at http://cals.arizona. edu/crops/cotton/comments/ Capril 
$1999 \mathrm{cc} . \mathrm{html}$.

Singh, Deepika B., Ramandeep Kaur M. Malhi and G. Sandhya Kiran, (2015). Assessing the impact of agronomic spacing conditions on biophysical and biochemical parameters along with yield and yield components in cotton, International Journal of Agronomy and Agricultural Research . 6 (1): 6-44.

Sisodia, R.I. and S.K. Khamparia, 2007. American cotton varieties as influenced by plant densities and fertility levels under rainfed conditions. J. Cotton Res. Dev. 21 (1):35-40.

Venugopalan, M.V., K.R. Kranthi, D. Blaise, Shubhangi Lakde, and K. Shankaranarayanan, (2013). High density planting system in cotton-the Brazil experience and Indian initiatives. Cotton Res. J. 5(2) 172-185. 